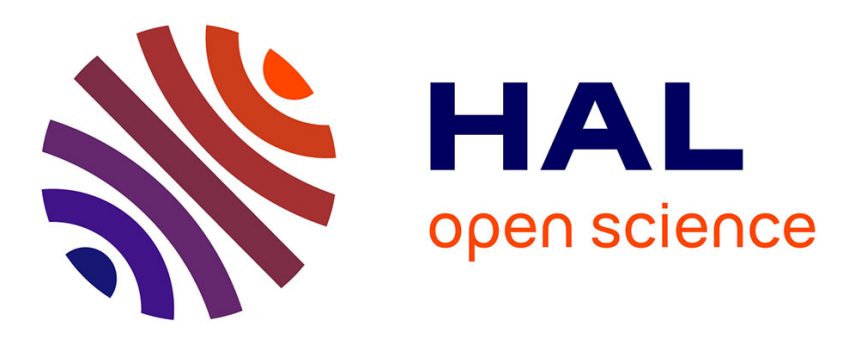

\title{
The Regularity of Rhythmic Primes In6luences Syntax Processing in Adults
}

Laure-Hélène Canette, Nathalie Bedoin, Philippe Lalitte, Emmanuel Bigand, Barbara Tillmann

\section{To cite this version:}

Laure-Hélène Canette, Nathalie Bedoin, Philippe Lalitte, Emmanuel Bigand, Barbara Tillmann. The Regularity of Rhythmic Primes In6luences Syntax Processing in Adults. Auditory Perception \& Cognition, 2019, 2 (3), pp.163-179. 10.1080/25742442.2020.1752080 . hal-03006065

\section{HAL Id: hal-03006065 https://hal.science/hal-03006065}

Submitted on 15 Nov 2020

HAL is a multi-disciplinary open access archive for the deposit and dissemination of scientific research documents, whether they are published or not. The documents may come from teaching and research institutions in France or abroad, or from public or private research centers.
L'archive ouverte pluridisciplinaire HAL, est destinée au dépôt et à la diffusion de documents scientifiques de niveau recherche, publiés ou non, émanant des établissements d'enseignement et de recherche français ou étrangers, des laboratoires publics ou privés. 


\section{The Regularity of Rhythmic Primes Influences Syntax Processing in Adults}

Laure-Hélène Canettea,b,c, Nathalie Bedoinn,d,e, Philippe Lalitte ${ }^{a, f}$, Emmanuel Biganda, ${ }^{*}$ and Barbara Tillmann ${ }^{\mathrm{b}, \mathrm{c}, *}$

a The Laboratory for Research on Learning and Development, CNRS-UMR 5022, University of Burgundy, Dijon, France;

b Lyon Neuroscience Research Center, Auditory Cognition and Psychoacoustics Team, CNRSUMR 5292, Inserm U 1028, Bron, France;

c University of Lyon 1, Lyon, France;

d Dynamique Du Langage Laboratory, CNRS-UMR 5596, University of Lyon 2, Lyon, France;

e Lyon Neuroscience Research Center, Integrative Multisensory Perception Action Cognition Team (IMPACT), CNRS-UMR, 5292, Inserm U 1028, Bron, France;

f Institut de Recherche en Musicologie, CNRS-UMR 8223, Sorbonne University, Paris, France

* Shared last authors

\section{KEYWORDS}

Rhythmic priming; syntax; music; temporal attention; inter-individual differences

\section{ABSTRACT}

Recent research has shown that auditory rhythmic stimulation improves subsequent syntax processing of speech in children with and without developmental language disorders. Sensitivity to grammatical errors is enhanced after regular rhythmic primes in comparison to irregular ones. Our present study investigated this rhythmic priming effect in healthy adults by using subtle grammatical errors as targets, aiming to fit with the high linguistic level of the participants. We also assessed whether participants' sensitivity to rhythmic priming on syntax processing was related to self-reported rhythmic skills and musical habits. Participants listened to rhythmic regular or irregular primes followed by blocks of six grammatically correct or incorrect sentences. Participants provided grammaticality judgments on each of the sentences, and response accuracy was analyzed. Furthermore, participants filled out a questionnaire about their musical skills, listening habits and music experience. Results revealed better grammaticality processing after regular rhythmic primes in comparison to irregular ones in healthy adults. Moreover, self-reported individual characteristics related to (1) rhythmic processing and synchronization, (2) amount of daily exposure to music, and (3) social bonding, contributed to significantly predict the rhythmic priming effect. Our findings confirm the influence of temporal regularities of musical primes on subsequent syntax processing, even when syntax processing is automatized (as in healthy young adults), and they point to inter-individual differences modulating the strength of this priming effect. We discuss results within the framework of the Dynamic Attending Theory suggesting that regular rhythms orient attentional resources over time, improving the processing of event structures, including for speech. 


\section{INTRODUCTION}

Rhythm has been defined as the temporal patterning of event durations in an auditory sequence (e.g., Large \& Palmer, 2002). In music, the rhythmic patterns allow for the abstraction of an underlying beat (i.e., a regular isochronous pulse). These temporal regularities facilitate the processing of musical events: rhythms with regular temporal structures (i.e., beat-based or metric rhythms) are better discriminated and reproduced than are irregular rhythms (i.e., non-metric rhythms) (Essens \& Povel, 1985; Grahn, 2012; Grahn \& Brett, 2007; Grahn \& Schuit, 2012). Similarly, in language, temporal regularities in the speech signal influence syntax processing: a rhythmically regular sentence facilitates syntactic ambiguity processing (Roncaglia-Denissen, Schmidt-Kassow, \& Kotz, 2013) and temporal intervals modulate the latency of syntactic error processing (Schmidt-Kassow \& Kotz, 2008).

As music and speech signals have temporal regularities, it has been suggested that music and speech processing share cognitive resources and mechanisms (e.g., Patel, 2008). Several studies have reported a link between rhythmic musical abilities and linguistic abilities in children, notably related to grammar skills (Gordon, Shivers et al., 2015), phonological awareness (Woodruff Carr, White-Schwoch, Tiernay, Strait, \& Kraus, 2014) and reading skills (Flaugnacco et al., 2014). The links between rhythmic musical and linguistic processing have been observed both in case of deficits and expertise. For instance, children with developmental language disorders (i.e., dyslexia and Specific Language Impairment) have been shown to present also impaired rhythmic processing of non-speech material, and these impaired performance levels are related to language performance levels (Colling, Noble, \& Goswami, 2017; Corriveau \& Goswami, 2009; Thomson \& Goswami, 2008). For healthy individuals, numerous studies have shown enhanced speech processing for musicians compared to non-musicians (e.g., syntax processing: Jentschke \& Koelsch, 2009; early sensory encoding of speech: Musacchia, Sams, Skoe, \& Kraus, 2007). Converging evidence has been provided by musical training studies focusing on rhythmic processing. Experimentally implemented musical training programs improved not only rhythmic abilities, but also phonological and reading skills in dyslexic children (Flaugnacco et al., 2015; Overy, 2000).

Beyond mid- and long-term effects of musical or rhythmic training on language processing, the link between rhythm and speech processing has been shown with short-term rhythmic priming studies, which also allows for studying pathological populations and open for perspectives of training and rehabilitation. Listening to a musical sequence with a strongly regular underlying beat improves syntax processing for subsequently presented sentences in typically developing children as well as children with developmental language disorders (Bedoin, Brisseau, Molinier, Roch, \& Tillmann, 2016; Canette et al., 2020b; Chern, Tillmann, Vaughan, \& Gordon, 2018; Przybylski et al., 2013). Rhythmic priming studies have also been conducted in adult patients with basal ganglia lesions or Parkinson's disease while measuring EEG. Listening to a rhythmically regular stimulus before listening to sentences restored the late positivity in response to grammatical violations (i.e., the P600) (Kotz \& Gunter, 2015; Kotz, Gunter, \& Wonneberger, 2005), which had been reported previously as missing in basal ganglia patients (Kotz, Frisch, von Cramon, \& Friederici, 2003). It also increased the P600 amplitude in response to grammatical errors listened by dyslexic and non-dyslexic adults (Canette et al., 2020a).

These studies can be understood within the framework of the Dynamic Attending Theory (Jones, 1976, 2019; Jones \& Boltz, 1989). According to this framework, internal oscillators (i.e., internal attending rhythms; Drake, Jones, \& Baruch, 2000) tend to synchronize with external regularities. Thanks to this synchronization, perceivers develop expectations about the temporal occurrence of next events, which then facilitates processing, segmentation and integration. At a neural level, cerebral rhythms have been shown to entrain with the temporal regularities of external stimuli and influence event processing (e.g., Ding \& Simon, 
2014; Fujioka, Trainor, Large, \& Ross, 2012; Giraud \& Poeppel, 2012; Large \& Snyder, 2009). Dynamic attending can be applied both to music (Large, Herrera, \& Velasco, 2015; Large \& Palmer, 2002) and speech perception (Kotz \& Schwartze, 2010; framed as the "Attentional Bounce Hypothesis" by Pitt \& Samuel, 1990). For example, listeners are more accurate in judging the pitch of rhythmically expected tones than unexpected ones (Jones, Moynihan, MacKenzie, \& Puente, 2002), and more accurate in spoken word perception when presented with a regular than an irregular inter-stress interval (Quené \& Port, 2005). In the rhythmic priming paradigm, the hypothesis is that the regular events in the musical prime entrain internal oscillators. After the musical prime, this then facilitates entrainment to the less regular speech signal, and consequently favors the processing of the speech signal and its syntactic structure (Przybylski et al., 2013; Schön \& Tillmann, 2015).

Previous research has shown that rhythmic abilities vary strongly between healthy individuals (Repp, 2010; Sowinski \& Dalla Bella, 2013) and are influenced by musical training (Grahn \& Schuit, 2012; Repp, 2010). Interestingly, inter-individual variabilities in rhythmic skills have been shown to contribute to explain the variability in the efficacy of a rhythmic intervention for patients with Parkinson's disease (i.e., gait improvement via rhythmic auditory stimulation) (Dalla Bella et al., 2017a). These findings outline the need for considering individual differences also in rhythmic priming studies for syntax processing.

Our present study investigated the effect of listening to regular rhythmic primes (in comparison to irregular primes) on subsequent syntax processing in healthy young adults. Our aim was to test whether the fully mature syntax processing system still benefits from the regularity of musical primes, and to assess the potential inter-individual differences in the strength of the rhythmic priming effect. In contrast to previous studies in children, we used more subtle and varied grammatical errors adapted to the linguistic and educational level of the participants, as well as a larger set of musical primes (not just one pair as in Przybylski et al., 2013; Chern et al., 2018). Based on the results reported for children (Bedoin et al., 2016; Chern et al., 2018; Przybylski et al., 2013), we predicted better performance in the grammaticality judgment task after regular primes than after irregular primes. Using questionnaires, we further investigated whether inter-individual differences related to musical skills, listening habits and music experience might influence the strength of the rhythmic priming effect on syntax processing in young healthy adults. Music and dance experience as well as self-reported rhythmic processing skills were expected to influence participants' potential sensitivity to the rhythmic regularity of the prime, as shown by differences in grammaticality judgments after regular and irregular primes.

\section{MATERIALS AND METHODS}

\section{Participants}

Twenty-five native French-speaking adults participated in the study (mean $=21.2$ years, $\mathrm{SD}=$ 1.76 , range $=19-26$ ). The study was performed in an educational context, in which students took part in a noninvasive laboratory experiment in exchange for course credit. They participated naïvely, and after the recording of the data, they could ask the experimenter about the purpose of the study to further their understanding of experimental psychology. Informed verbal consent was obtained from all participants prior to taking part in the experiment. The study was anonymous and fully respected the Helsinki Declaration, Convention of the Council of Europe on Human Rights and Biomedicine. 


\section{Material}

\subsection{Musical Stimuli}

Four rhythmically regular sequences and four irregular sequences were used. The four regular sequences were constructed on the basis of a 4/4 meter and a 120 BPM tempo, that is with an underlying inter-beat-interval of $500 \mathrm{~ms}$ (i.e., $2 \mathrm{~Hz}$ ). These sequences were formed by 4 layers of rhythmic patterns, each based on different inter-beat-intervals, leading to a four-level rhythmic hierarchy. To vary and characterize the sequences in timbres, each layer was played by one (sometime two) percussion instrument(s) (i.e., bass drum, snare drum, tom-tom, and cymbal). All sequences were based on MIDI VST instruments timbres. Four of the sequences also contained some samples of electronic sounds. Each sequence was composed of one cycle of 16 beats that was repeated identically four times, thus leading to a duration of 32 seconds. To create a feeling of completion at the end of the sequence, the first beat of the cycle was added again at the end, thus extending the sequence for 2 seconds with a short reverberation effect, leading to the total duration of 34 seconds. Note that a short rhythmic pattern or a percussion sound was added at the end of a cycle to reinforce the sensation of formal periodicity.

The four rhythmically irregular sequences were derived from the four rhythmically regular ones. The layers, the percussion sounds, the total duration as well as the duration of each event were identical. In each layer, the number of percussive events was the same as for the regular sequences, but reordered to obtain a maximum of rhythmic irregularity. In this way, it was impossible to extract perceptively an underlying pulse or a regular metric. In addition, the process of reordering the percussive impacts was made across the entire sequence. Thus, the rhythmically irregular sequences were not characterized by repeated cycles of 16 beats.

All sequences were recorded with Cubase 4 and Kontakt 3 VST instruments. They were exported in 16 bits/48 $000 \mathrm{~Hz}$ mono wav files and normalized in loudness (dBA). See supplemental material for examples.

\subsection{Linguistic Stimuli}

The linguistic material was composed of 96 sentences, which were either grammatically correct (48) or not (48) (see Appendix A). We first created 48 correct sentences and derived an incorrect sentence from each correct sentence. Incorrect sentences contained subtle morpho-syntactic errors (aiming to avoid ceiling performance) covering errors regarding tense, prepositions, and person agreement. Sentences were separated into two lists (List A and List B) of 48 sentences (24 correct sentences and 24 incorrect sentences) to avoid participants listening to a same sentence in its correct and incorrect versions. Each correct sentence of List A was matched in number of words, number of syllables, and word's lexical frequency (Lexique 3; New, Pallier, Ferrand, \& Matos, 2001) to a correct sentence of List B. The mean number of words per sentence was $10.33(\mathrm{SD}=1.83$, range $=6$ to 15$)$ in list $\mathrm{A}$ and 10.35 $(\mathrm{SD}=1.80$, range $=6$ to 15$)$ in list $\mathrm{B}$. The mean number of syllables was $13.67(\mathrm{SD}=1.75$, range $=10$ to 18$)$ in list $\mathrm{A}$ and $13.75(\mathrm{SD}=1.72$, range $=10$ to 17$)$ in list $\mathrm{B}$. Half of the participants heard the correct sentences of List A and the incorrect sentences of List $B$, and the reverse was done for the other half of the participants. Overall the 96 sentences, the mean number of words per sentence was $10.34(\mathrm{SD}=1.81$, range $=6$ to 15 ) and the mean number of syllables per sentence was $13.71(\mathrm{SD}=1.73$, range $=10$ to 18$)$. Sentences were spoken by a female native speaker of French at a natural speed of production, and were normalized in loudness. The mean duration of sentences was $2574 \mathrm{~ms}(\mathrm{SD}=379$, range $=1676$ to 3466 ), with $2569 \mathrm{~ms}(\mathrm{SD}=403$, range $=1825$ to 3466) in list $\mathrm{A}$ and $2579 \mathrm{~ms}(\mathrm{SD}=359$, range $=1676$ to 3389 ) in list B. 


\section{Procedure}

The 48 sentences were presented by blocks of six sentences (three grammatical sentences, three ungrammatical sentences). Sentence distribution in the blocks and sentence order in each block were randomized for each participant. The experiment consisted in 8 blocks, each preceded by a musical prime. Half of the blocks were preceded by a regular prime and half by an irregular prime. Primes were arranged in a pseudo-randomized order. Two consecutive blocks were presented with the same rhythmic prime type (regular or irregular), but with two different musical prime sequences. Then, the two following blocks changed to the other priming condition. A given prime did not follow its matched regular or irregular version. Half of the participants started with regular rhythmic primes and half with irregular primes. Participants were asked to listen to the music and to perform the grammaticality judgment task on each sentence. They triggered each prime and each sentence by pressing the space bar and judged each sentence for grammaticality by pressing one of two response buttons. Response choices were indicated on the keyboard as well as on the computer screen by the words "grammatical" and "ungrammatical" associated with the colors green and red. There was a break in the middle of the experiment. Participants were tested individually in a testing room. The experiment was run using the software OpenSesame (Mathôt, Schreij, \& Theeuwes, 2012), and stimuli were presented via headphones at a comfortable loudness level, which could be adapted if requested by the participant.

At the end of the experimental session, participants completed a questionnaire about their musical skills and listening habits. This questionnaire was partly based on Peretz et al. (2008) and was composed of various items investigating music and dance practice as well as music in everyday life (i.e., open questions, yes/no questions and five-point scales). Participants also completed the BMRQ (Barcelona Music Reward Questionnaire) (MasHerrero, Marco-Pallares, Lorenzo-Seva, Zatorre, \& Rodriguez-Fornells, 2013; see Saliba et al., 2016 for the French version used here). The BMRQ investigates five main facets of musical reward experience in individuals: musical seeking, emotion evocation, mood regulation, social reward and sensory-motor. For a total of 20 questions, it contains four items for each of the five facets. Participants indicated the level of agreement with each item by using a five-point scale ranging from "fully disagree" (1) to "fully agree" (5).

\section{Data Analyses}

Performance was analyzed with signal detection theory calculating discrimination sensitivity with $d^{\prime}$ and response bias with $c$ for each participant and for each prime condition ${ }^{1}$. Based on previous data leading to predict better performance after regular primes, performance $\left(d^{\prime}\right)$ was analyzed by one-sided paired $t$-tests, with either participants $\left(t_{1}\right)$ or sentences $\left(t_{2}\right)$ as the random variable. In addition, potential differences in response bias $c$ were assessed with twosided paired $t$-tests and participants as the random variable. We reported effect sizes in terms of $\mathrm{d}_{\mathrm{z}}$ or $\mathrm{d}$ using $\mathrm{G}^{*}$ Power software (Faul, Erdfelder, Lang, \& Buchner, 2007), with the following proposed categories for interpretation: small $=0.20$, medium $=0.50$, large $=0.80$ (Cohen, 1988).

\footnotetext{
1 These analyses are based on the proportions of hits (i.e., proportion of correct responses for ungrammatical sentences, $\mathrm{p}$ [hits]) and false alarms (i.e., errors for grammatical sentences, $\mathrm{p}$ [FAs]) after regular and irregular primes. $D^{\prime}$ is defined as $\mathrm{z}(\mathrm{p}[\mathrm{hits}])-\mathrm{z}(\mathrm{p}[\mathrm{FAs}])$, and response bias $c$ as $-0.5[\mathrm{z}(\mathrm{p}[\mathrm{hits}])+\mathrm{z}(\mathrm{p}[\mathrm{FAs}])]$; see Macmillan and Creelman (1991) for more details. The correction of the $d^{\prime}$ and $c$ measures used 0.01 for cases without false alarms and 0.99 for the maximum number of hits.
} 
Aiming to predict the difference between performance $\left(d^{\prime}\right)$ after regular primes and performance after irregular primes, we ran multiple regression analyses (forward stepwise) with participants' responses in the questionnaire as predictors. The questions were separated into three subsets (see Appendix B) and analyzed with three regression analyses: (1) number of years of music training and of dance training (i.e., two questions), (2) 17 questions about "music in everyday life" related to pitch and rhythm processing as well as to musical exposure, and (3) items of the BMRQ (i.e., 20 questions). We performed supplementary regression analyses on each of the five BMRQ subscales (i.e., four questions each) aiming to confirm results of the regression on all BMRQ items.

\section{RESULTS}

\section{Grammaticality Judgments}

Participants' performance was better after regular primes (mean $d^{\prime}=2.42$, SD $=0.76$ ) than after irregular primes (mean $\left.d^{\prime}=2.08, \mathrm{SD}=0.86\right), t_{1}(24)=-1.82, p=.041, \mathrm{~d}_{\mathrm{z}}=0.37$. Analysis on sentences confirmed this significant difference, $t_{2}(47)=-1.97, p=.027, \mathrm{~d}_{\mathrm{z}}=0.28$.

Bias $c$ did not differ between the two prime conditions, $p=.397$. Response bias $c$ was significantly above 0 (i.e., bias to respond "grammatical") for both the regular condition (mean $c=0.54, \mathrm{SD}=0.45), t(24)=15.91, p<.001, \mathrm{~d}=1.14$, and the irregular condition (mean $c=$ $0.45, \mathrm{SD}=0.42), t(24)=12.10, p<.001, \mathrm{~d}=0.97$.

To further investigate whether the priming effect changed across the experimental session, performance was calculated separately for the first part and for the second part of the experiment (i.e., before and after the break in the middle of the experiment). In the first part of the experiment, the difference between the two prime conditions did not reach significance (mean regular $d^{\prime}=2.23$, mean irregular $d^{\prime}=2.14$ ), $p=.358$. In the second part of the experiment, performance was better after regular primes (mean $d^{\prime}=3.00$ ) than after irregular primes (mean $d^{\prime}=2.50$ ), $t_{1}(24)=-2.26, p=.017, \mathrm{~d}_{\mathrm{z}}=0.45$. Performance for irregular primes did not differ significantly between the two parts of the experiment (mean $d^{\prime}$ difference $=$ 0.36), $p=.152$, whereas performance after regular primes improved significantly in the second part (mean $d^{\prime}$ difference $\left.=0.77\right), t_{1}(24)=-3.30, p=.003, \mathrm{~d}_{\mathrm{z}}=0.67$.

\section{Regression Analyses}

The first regression analysis with number of years of music and dance training did not result in a significant regression model (no predictor ended up in the regression equation).

The second regression analysis with questions about "music in everyday life" resulted in a significant regression model, $\mathrm{R}^{2}=0.46, F(4,20)=4.31, p=.011$. The item about the amount of music listening ("How many hours do you listen to music per day?") was a significant positive predictor (beta $=0.30, t(20)=2.28, p=.033$ ). The item about the incapacity to follow music rhythm ("Indicate whether this sentence applies to you: I don't manage to follow music rhythm") just fell short of significance as a negative predictor (beta $=$ $-0.88, t(20)=-1.89, p=.074)$.

The third regression analysis with all items of the BMRQ led to a significant regression model $^{2}, \mathrm{R}^{2}=.74, F(6,17)=8.17, p<.001$. Two BMRQ items predicted positively the priming effect: "When I hear a tune I like a lot I can't help tapping or moving to its beat" (beta $=0.57$, $t(17)=3.82, p=.001)$ and "Music makes me bond with other people" (beta $=0.44, t(17)=$

\footnotetext{
2 Note that for this analysis we removed one participant who used one scale incongruently with another response (she indicated listening rarely to music with 1 - out of 5 - while indicating 6 hours of daily music listening in the open question).
} 
3.54, $p=.003)$. Moreover, two BMRQ items predicted negatively the priming effect: "I sometimes feel chills when I hear a melody that I like" (beta $=-0.37, t(17)=-3.06, p=.007$ ), and "I can't help humming or singing along to music that I like" (beta $=-0.40, t(17)=-2.37, p$ $=.030$ ). Finally, the BMRQ item "In my free time I hardly listen to music" just fell short of significance (beta $=0.34, t(17)=2.01, p=.060$ ), but was not significant in the additional regression model run separately on the subscale musical seeking (regression model was not significant, no predictor ended up in the regression equation). In contrast, the other four items were confirmed as significant predictors in the regressions focusing on their respective subscales (sensory-motor, social reward, emotion evocation). See Table 1 for more details.

Table 1. Mean, standard deviation, minimum and maximum for each significant question in the regression analyses. Items 1 and 2 are in the second regression analysis, items 3 to 7 are in the third regression analysis.

\begin{tabular}{|c|c|c|c|c|}
\hline Items & $\begin{array}{c}\text { Mean (or } \\
\text { number of yes / } \\
\text { no responses) }\end{array}$ & $\begin{array}{l}\text { Standard } \\
\text { deviation }\end{array}$ & $\begin{array}{l}\text { Min- } \\
\text { Max }\end{array}$ & beta \\
\hline $\begin{array}{l}\text { 1. How many hours do you listen to music per day? [in } \\
\text { minutes] }\end{array}$ & 119 & 82 & $30-360$ & 0.30 \\
\hline $\begin{array}{l}\text { 2. I don't manage to follow music rhythm. Indicate } \\
\text { whether this sentence applies to you }\end{array}$ & 4 “yes"; 21 "no" & & & -0.88 \\
\hline $\begin{array}{l}\text { 3. When I hear a tune I like a lot I can't help tapping or } \\
\text { moving to its beat }\end{array}$ & 4.08 & 1.02 & $1-5$ & 0.57 \\
\hline 4. Music makes me bond with other people & 3.67 & 1.01 & $1-5$ & 0.44 \\
\hline $\begin{array}{l}\text { 5. I sometimes feel chills when I hear a melody that I } \\
\text { like }\end{array}$ & 3.88 & 0.90 & $2-5$ & -0.37 \\
\hline $\begin{array}{l}\text { 6. I can't help humming or singing along to music that } \\
\text { I like }\end{array}$ & 4.33 & 0.92 & $1-5$ & -0.40 \\
\hline 7. In my free time I hardly listen to music & 1.5 & 0.72 & $1-4$ & 0.34 \\
\hline
\end{tabular}

\section{DISCUSSION}

Previous behavioral studies conducted in children (Bedoin et al., 2016; Chern et al., 2018; Przybylski et al., 2013) and electrophysiological studies in adult patients (Basal ganglia lesions: Kotz et al., 2005; Parkinson disease: Kotz \& Gunter, 2015; dyslexia in adults: Canette et al., 2020a) have reported a beneficial effect of a regular rhythm on subsequent syntax processing. Our study extends this finding to healthy adults by measuring their performance in a grammaticality judgment task with a difficulty level adapted to their linguistic and educational level (University students). The results suggest that the auditory perception of rhythmic regularities immediately before speech perception can be efficient even in the case of highly automatized and non-impaired linguistic skills, at least regarding syntax processing in healthy young adults. Moreover, additional analyses showed that the benefit of the regular rhythmic prime built up over the experimental session (see below for further discussion).

The rhythmic priming effect can be interpreted within the framework of the Dynamic Attending Theory (Jones, 1976, 2019; Jones \& Boltz, 1989). The regular events in the musical prime provide predictable cues that may allow boosting and entraining internal oscillators. Temporal expectations are assumed to develop over time following the strong metrical structure of the primes. This ongoing entrainment might then benefit to the entrainment to 
the subsequent speech signal and in particular its syntax processing, notably as speech and syntax processing also requires entrainment and temporal attention (Gordon, Jacobs, Schuele, \& McAuley, 2015; Kotz \& Schwartze, 2010; Port, 2003; Quené \& Port, 2005; Schmidt-Kassow \& Kotz, 2008). The present results showed that even the healthy adult brain can benefit from the modulation of temporal attention by regular rhythmic primes. It is relevant to note that the used tempo of $2 \mathrm{~Hz}$ for the regular rhythmic primes corresponds approximately to the rate of stressed syllables in speech (Arvaniti, 2009; Dauer, 1983), and is close to the preferred spontaneous tempo in young adults (McAuley, Jones, Holub, Johnston, \& Miller, 2006). Future research should now investigate how specific the effect is to the $2 \mathrm{~Hz}$ rate related to either the speech rate or the preferred tempo, and/or how flexible it is to extend to slower or faster tempi as well as to potential mismatch between speech rate and preferred tempo.

In contrast to an explanation in terms of dynamic attending and rhythmic processing, it might be argued that the beneficial effect of the rhythmic regular prime could operate via increased arousal level and the induction of positive mood, as suggested by the arousal-andmood-hypothesis (e.g., Schellenberg, 2005). This hypothesis would suggest that the rhythmic priming effect is a general effect rather than a specific effect on sequencing or syntax processing in particular. However, recent studies have reported that the rhythmic priming effect does not extend to tasks that do not require sequencing and segmentation, such as nonlinguistic control tasks requiring mathematical and visuo-spatial processing (Chern et al., 2018), as well as a semantic evocation task, for which textural sound sequences (judged as sadder than regular sequences) were more efficient (Canette et al., 2020b). While these studies were conducted with children, it seems plausible to expect a similar pattern in adults, even though future research needs to further investigate this.

In the present study, the comparison between regular and irregular sequences shows a relative facilitation effect, and it does not yet allow for disentangling whether the difference is due to a benefit of the regular prime or a cost of the irregular prime (or both). The comparison of regular and irregular rhythmic sequences is a first step in priming approaches, which has then been followed by the investigation of costs and benefits (despite the difficulty of defining appropriate baseline conditions) in psycholinguistics (see Jonides \& Mack, 1984), music cognition (see Tillmann, Janata, Birk, \& Bharucha, 2003) as well as in the investigation of the rhythmic priming effect on syntax processing in children. For this later one, the first studies only compared regular versus irregular primes (Chern et al., 2018; Przybylski et al., 2013) and subsequent studies have provided evidence for the benefit of the regular prime over more neutral baseline primes or a silent condition (Bedoin et al., 2016; Canette et al., 2020b). Future research needs now to further investigate this more specific comparison also in adult listeners, but our additional analyses over the course of the experimental session provide some first response in favor of a beneficial effect of the regular prime.

The rhythmic priming effect (i.e., the difference between regular and irregular primes) became stronger in the second part of the experiment, mainly because performance after regular primes increased from the first to the second part of the experiment. This result is in agreement with the interpretation of a beneficial effect of regular primes rather than a disturbing effect of irregular primes. It is also in agreement with previous rhythmic priming studies in children, showing a benefit provided by regular rhythmic primes on syntax processing in comparison to neutral baseline conditions (environmental sounds: Bedoin et al., 2016; textural sounds and silence: Canette et al., 2020b), therefore excluding an alternative explanation solely invoking a cost of processing due to irregular primes. In the present study, participants benefited more strongly from regular primes over the time course of the experiment, possibly also because the increased familiarity with the musical sequences might have helped extracting the underlying $2 \mathrm{~Hz}$ beat and synchronizing to the primes. To explore this hypothesis, future research could investigate whether a familiarization phase before the experiment could reinforce the priming effect. For example, participants could listen to the primes or synchronize to them with externalized tapping, as it has been shown that body 
movement facilitates the extraction of temporal structures and pulse (e.g., Su \& Pöppel, 2012). A general musical rhythmic training session could also be proposed before the experiment (as for example in Hidalgo, Falk, \& Schön, 2017, with hearing-impaired children), aiming to strengthen the priming effect. These future extensions of the rhythmic priming implementation in adults are particularly interesting as the effect size measured for the entire experiment does not seem to be as strong as previously reported effect sizes for typically developing children as well as dyslexic and SLI children (Bedoin et al., 2016; Chern et al., 2018; Przybylski et al., 2013) ${ }^{3}$. Interestingly, for the adults, the effect emerged over the experimental session. These findings suggest that the here implemented rhythmic priming effect for syntax might be more efficient in a developmental or a pathological context, and/or with increased familiarization to the material ${ }^{4}$.

Our results further revealed that inter-individual differences regarding self-reported musical skills and listening habits contributed to the strength of the rhythmic priming effect. Specifically, multiple regression analyses showed that items related to (1) rhythmic processing and synchronization, (2) amount of daily exposure to music, and (3) feeling of social bonding through music, contributed to predict the rhythmic priming effect.

Although beat tracking and synchronization skills are general human characteristics, they vary across the general population (Repp, 2010; Sowinski \& Dalla Bella, 2013). Using regression analyses, we pointed out a link between the rhythmic priming effect on syntax processing and self-reported rhythmic interest and abilities: the desire to move and synchronize with music predicted positively the rhythmic priming effect, and the incapacity to follow musical rhythm tended to be a negative predictor of the rhythmic priming effect. In other words, the more the participants reported to be sensitive to rhythm, the more strongly the difference between the two priming conditions favored regular primes over irregular primes. The item about the desire to move and to synchronize with music can be linked to the concept of "groove". It has been defined as a cognitive temporal phenomenon characterized by beat perception and synchronized body responses (Pressing, 2002) and also by the desire to move with music (Madison, 2006). Some studies have shown that synchronization performance is enhanced by high beat saliency (Tranchant, Vuvan, \& Peretz, 2016) and more generally by high-groove music (Leow, Parrott, \& Grahn, 2014). Various musical features, such as repetitive rhythm, syncopation, and beat salience have been proposed to contribute to groove (Stupacher, Hove, \& Janata, 2016). The regular rhythmic primes in the present experiment included these various musical features contributing to groove and improving synchronization. The synchronization might favor signal sequencing and anticipation, which are central for syntax processing. To further understand the potential link between rhythmic abilities and the rhythmic priming effect, future research should go beyond self-reported responses and measure inter-individual differences in beat perception and synchronization with objective evaluation tools for perception (e.g., Beat Alignment Test, Iversen \& Patel, 2008; Profile of Music Perception Skills, Law \& Zentner, 2012) and production (e.g., Battery for the Assessment of Auditory Sensorimotor and Timing Abilities, Dalla Bella et al., 2017b).

\footnotetext{
${ }^{3}$ For children, the following effect sizes have been reported: Chern et al.: $\mathrm{d}=0.57$; Przybylski et al.: partial eta $2=0.34$ and 0.14 for SLI and dyslexia children, respectively; Bedoin et al.: partial eta2 $=0.14$.

4 Power analyses confirmed that the effect was weaker for healthy adults than for children. Indeed, in Canette et al. (2020b) for example, with $\mathrm{N}=16$ and $\mathrm{d}_{\mathrm{z}}=0.62$, the power was 0.76 , and in the present study with $\mathrm{N}=25$ and $\mathrm{d}_{\mathrm{z}}=0.37$, we reached a power of 0.56 (with alpha $=0.05$, one-tailed tests). For a power of 0.80 , with the same effect size $\left(d_{z}=0.37\right), 47$ participants would be needed (calculated with $\mathrm{G}^{*}$ Power).
} 
In contrast to questionnaire items relative to rhythm processing, items relative to pitch processing and those that have been reported as indicative for congenital amusia ${ }^{5}$ (Peretz et al., 2008) did not emerge as positive predictors for the rhythmic priming effect. This specific predictive capacity of rhythm-related items in comparison to pitch-related items is in agreement with a recent rhythmic priming study measuring Evoked Related Potentials (ERPs) for words with a stress pattern that either matched or mismatched the preceding prime (Fotidzis, Moon, Steel, \& Magne, 2018). Beyond observing an increased negativity for words with mismatching stress pattern, this study reported a correlation between speech rhythm sensitivity (i.e., the ERP difference between match and mismatch conditions) and musical rhythm aptitude, but failed to found any correlation with tonal abilities (both rhythmic and tonal abilities were objectively assessed with a comparison task on melody pairs). Converging evidence can also be found in the beneficial effect of rhythmic cues on gait in patients with Parkinson disease: even though patients show an overall beneficial effect of the rhythmic cue on gait, inter-individual differences in the extent of the effect of the rhythmic stimulation were reported (Dalla Bella, Dotov, Bardy, \& Cochen de Cock, 2018). One explanation for these differences was related to inter-individual differences in rhythmic skills: relatively spared abilities to track the beat favored a positive response to rhythmic cueing (Cochen de Cock et al., 2018; Dalla Bella et al., 2017a, 2018).

Beyond the items related to rhythmic processing and synchronization, our analyses revealed that an item about social bonding (i.e., considering music as a way to create social links) was a positive predictor for the rhythmic priming effect. Relations between social bonding and temporal processing have been documented previously: experimental studies showed that joint music making, singing and dancing enhance prosocial behavior in children (Kirschner \& Tomasello, 2010), and that moving together in synchrony increases cooperation and affiliation between adults (Hove \& Risen, 2009; Valdesolo, Ouyang, \& DeSteno, 2010; Wiltermuth \& Heath, 2009).

Finally, our analyses also revealed the amount of self-reported daily exposure to music as a positive predictor for the rhythmic priming effect. In contrast, we did not find a significant contribution of music and dance training as measured by years of formal training. This might be linked to the fact that the range of music and dance training in our study was not systematically manipulated; we tested a mixed group of students and did not select highly trained musicians or dancers, for example. A more intense practice of music and dance (i.e., as professional musicians or dancers) or the age at beginning of musical practice (early trained musicians are better at reproducing the temporal structure or rhythms; Bailey \& Penhune, 2010) could be considered in future studies.

While the rhythmic priming effects and the regression results discussed up to here have been rather expected based on previously reported findings, our analyses revealed two less-expected results: two items related to emotion and singing predicted negatively the rhythmic priming effect on syntax processing. A possible explanation is that the tendency to engage in a listening attitude mostly guided by emotion or oriented to emotional aspects as well as focusing on the pitch dimension when listening to the musical primes could have disturbed the benefit of the regular rhythm and its effect on sequencing and segmentation, which are required in syntax processing. There are different forms of musical engagement during listening, and two networks have been distinguished: a network for external engagement (e.g., rhythm processing) and a network for internal engagement (e.g., emotional processes) (Janata, 2009). Even though both networks are involved in music listening, it might be that listeners differ in the potential asymmetry of the involvement of these networks. Assigning disproportionate importance to pitch and/or emotional processing might draw

\footnotetext{
${ }^{5}$ For example: I hardly recognize tunes without the help of lyrics; I rarely detect when someone signs out-of-tune.
} 
attention away from the prime rhythm and meter and contribute to also reduce the potential influence of the rhythmic regularity of the prime.

\section{CONCLUSION}

Our study has shown that auditory rhythmic stimulation of syntax processing can be observed in healthy adults required to judge subtle grammatical manipulations. This result shows that syntax processing can be improved via previously heard musical regularities, even when it is an unimpaired and automatized capacity. Furthermore, our results suggest that the strength of the rhythmic priming effect might be related to some individual characteristics about rhythmic synchronization, social bonding in musical contexts, and daily exposure to music. Taken together, they provide perspectives to potentially increase rhythmic priming effects via rhythmic training, enhanced music listening or motor synchronization activities in both healthy and clinical populations.

\section{ACKNOWLEDGMENTS}

We thank Audrey Sarafian for help in running participants, Isabelle Peretz for sharing her questionnaire with us and Anna Fiveash for discussions and additional material analyses. The team "Auditory cognition and psychoacoustics" is part of the LabEx CeLyA ("Centre Lyonnais d'Acoustique", ANR-10-LABX-60) and L-HC is supported by a post-doctoral grant of the LabEx CeLyA.

\section{DISCLOSURE STATEMENT}

The authors declare that there is no conflict of interest. 


\section{APPENDIX A}

\begin{tabular}{|c|c|c|}
\hline Number & List & Sentence \\
\hline \multirow[t]{2}{*}{1} & A & Aucun règlement n'interdit -/pas de venir ici. \\
\hline & $\mathrm{B}$ & Aucun professeur n’a -/pas donné les résultats. \\
\hline \multirow[t]{2}{*}{2} & A & Cette personne que je ne connais pas fait-elle/il partie du groupe? \\
\hline & $\mathrm{B}$ & La personne qui vient d'entrer est-elle/il déjà venue chez vous? \\
\hline \multirow[t]{2}{*}{3} & A & S'il avait/aurait vu ta lettre il t'aurait répondu. \\
\hline & $\mathrm{B}$ & S'il pouvait/pourrait nous donner sa réponse ce serait bien. \\
\hline \multirow[t]{2}{*}{4} & A & Sans moi ils seraient/auraient restés à la maison toute la journée. \\
\hline & $\mathrm{B}$ & D’après vous elle serait/aurait passée par ici la semaine dernière. \\
\hline \multirow[t]{2}{*}{5} & A & Bien qu'il se soit/s'est couché tôt il est encore fatigué. \\
\hline & B & 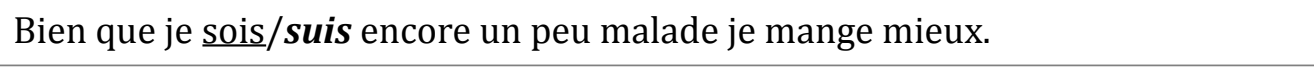 \\
\hline \multirow[t]{2}{*}{6} & A & Il m’a apporté tout ce dont/que j'ai besoin pour cuisiner. \\
\hline & $\mathrm{B}$ & Je me souviens très bien de ce dont/que nous avons parlé hier. \\
\hline \multirow[t]{2}{*}{7} & A & Ils cherchent ce/qu'est-ce qui serait le plus simple pour résoudre leur situation. \\
\hline & $\mathrm{B}$ & Nous lui avons demandé ce/qu'est-ce que nous pourrions faire pour l'aider. \\
\hline \multirow[t]{2}{*}{8} & A & Il est allé au cinéma avec des copains $\underline{\mathrm{de}} / \grave{a}$ son frère. \\
\hline & B & Hier soir il a réparé la voiture $\underline{\text { de }} / \grave{a}$ sa grande sœur. \\
\hline \multirow[t]{2}{*}{9} & A & Nous avons planté cet arbre avec des voisins àd/de nous. \\
\hline & $\mathrm{B}$ & Nous sommes partis en vacances avec des amis à $/ d e$ moi. \\
\hline \multirow[t]{2}{*}{10} & A & Il a demandé à/de venir chez moi jeudi prochain. \\
\hline & $\mathrm{B}$ & Les parents ont demandé à/de voir la nouvelle classe. \\
\hline \multirow[t]{2}{*}{11} & A & Je suis obligé de/à partir très tôt demain matin. \\
\hline & $\mathrm{B}$ & Je suis obligé de/à rouler lentement sur cette route. \\
\hline \multirow[t]{2}{*}{12} & A & Je n'ai pas réussi mon examen moi non plus/aussi. \\
\hline & B & Il n’a pas changé d'appartement lui non plus/aussi. \\
\hline \multirow[t]{2}{*}{13} & A & C'est moi qui ai/a oublié les clefs sur la porte. \\
\hline & $\mathrm{B}$ & C'est moi qui ai / $\boldsymbol{a}$ fait le repas pour ce soir. \\
\hline \multirow[t]{2}{*}{14} & A & J'irai chez le/au boulanger demain matin. \\
\hline & $\mathrm{B}$ & J'ai rendez-vous chez le/au dentiste aujourd'hui. \\
\hline \multirow[t]{2}{*}{15} & A & Il s'endort tellement -/qu'il est fatigué. \\
\hline & $\mathrm{B}$ & Il a tout mangé tellement -/qu'il avait faim. \\
\hline \multirow[t]{2}{*}{16} & A & Je ne sais pas ce qu'il/qui faut acheter pour finir les travaux. \\
\hline & $\mathrm{B}$ & Vous m’avez expliqué ce qu'il/qui convient de faire dans ce cas. \\
\hline
\end{tabular}




\begin{tabular}{lll}
\hline 17 & A & J'espère que vous avez/ayez pris la meilleure décision. \\
\hline 18 & B & Je crois que nous avons/ayons bien choisi le cadeau. \\
\hline A & Je ne pense pas que nous ayons/avons le temps de nous arrêter. \\
\hline 19 & B & Je ne suis pas sûr que vous ayez/avez choisi le bon chemin. \\
\hline A & Parmi tes élèves il y en a -/des qui n'ont pas rendu leur devoir. \\
\hline B & Demain ils vont tous venir mais il y en a -/des qui seront en retard. \\
\hline 21 & A & Il a choisi une date car personne ne/- voulait décider. \\
\hline B & A cause du bruit dehors personne ne/-vous a entendu. \\
\hline 22 & B & Ils m'ont confirmé que cela ne les/leur dérangeait pas. \\
\hline A & Les enfants leur/les ont montré un nouveau tour de magie. \\
\hline 23 & B & Elle leur/les a demandé de faire les courses ce matin. \\
\hline A & Il n'a pas pensé à/de venir avec un cadeau. \\
\hline 24 & B & Je n'ai jamais songé à/d'y aller en voiture. \\
\hline A & $\begin{array}{l}\text { Le monsieur renseigne cette personne et lui parle du quartier / Le monsieur } \\
\text { renseigne et parle du quartier à cette personne. }\end{array}$ \\
\hline
\end{tabular}

Errors are indicated in bold and italics. 


\section{APPENDIX B}

\section{(1) Number of years of music training and of dance training}

1. Do you play or have you ever played (a) music instrument(s)? If yes, what kind of music instrument and for how long?

2. Do you take or have you ever taken dancing classes? If yes, what kind of dance and for how long?

(2) Questions about "music in everyday life", related to pitch, rhythm, musical exposure and amusia

Item Response options

1. Do you sing in private? (in the car, in the shower, $\quad$ From 1 (never) to 5 (very often) etc.).

2. Do you sing in public? (with friends, karaoke, etc.) From 1 (never) to 5 (very often)

3. Do you think you sing in tune? Yes/No

4. I have difficulties recognizing a song without lyrics. From 1 (fully disagree) to 5 (fully agree)

5. I am rarely able to notice when someone sings out of From 1 (fully disagree) to 5 (fully agree) tune.

\begin{tabular}{|c|c|}
\hline 6. Do you dance? & From 1 (never) to 5 (very often) \\
\hline 7. Do you intentionally listen to music? & From 1 (never) to 5 (very often) \\
\hline 8. How many hours do you listen to music per day? & \\
\hline 9. Do you think you have the "sense of rhythm"? & From 1 (not at all) to 5 (a lot) \\
\hline 10. Is it easy for you to follow the rhythm of a song? & From 1 (not easy) to 5 (very easy) \\
\hline $\begin{array}{l}\text { 11. Could you notice when someone produces a wrong } \\
\text { note? }\end{array}$ & Yes/No \\
\hline $\begin{array}{l}\text { Indicate whether this sentence applies to you: } \\
\text { 12. A relative, a friend or a teacher told me that I do } \\
\text { not have a musical ear. } \\
\text { 13. I don't manage to follow music rhythm. } \\
\text { 14. I have difficulties reproducing by singing tones } \\
\text { played on the piano. } \\
\text { 15. For me, music is like noise. } \\
\text { 16. Music is like speech in a foreign language. } \\
\text { 17. I find most music irritating. }\end{array}$ & $\begin{array}{l}\text { Yes/No } \\
\text { Yes/No } \\
\text { Yes/No } \\
\text { Yes/No } \\
\text { Yes/No } \\
\text { Yes/No }\end{array}$ \\
\hline
\end{tabular}




\section{REFERENCES}

Arvaniti, A. (2009). Rhythm, timing and the timing of rhythm. Phonetica, 66(1-2), 46-63. Bailey, J. A., \& Penhune, V. B. (2010). Rhythm synchronization performance and auditory working memory in early- and late-trained musicians. Experimental Brain Research, 204(1), 91-101.

Bedoin, N., Brisseau, L., Molinier, P., Roch, D., \& Tillmann, B. (2016). Temporally regular musical primes facilitate subsequent syntax processing in children with Specific Language Impairment. Frontiers in Neuroscience, 10, 245.

Canette, L.-H., Fiveash, A., Krzonowski, J., Corneyllie, A., Lalitte, P., Thompson, D., Trainor, L., Bedoin, N., \& Tillmann, B. (2020a). Regular rhythmic primes boost P600 in grammatical error processing in dyslexic adults and matched controls. Neuropsychologia, 138, 107324.

Canette, L.-H., Lalitte, P., Bedoin, N., Pineau, M., Bigand, E., \& Tillmann, B. (2020b). Rhythmic and textural musical sequences differently influence syntax and semantic processing in children. Journal of Experimental Child Psychology, 191, 104711.

Chern, A., Tillmann, B., Vaughan, C., \& Gordon, R. L. (2018). New evidence of a rhythmic priming effect that enhances grammaticality judgments in children. Journal of Experimental Child Psychology, 173, 371-379.

Cochen de Cock, V., Dotov, D. G., Ihalainen, P., Bégel, V., Galtier, F., Lebrun, C., Picot, M. C., Driss, V., Landragin, N., Geny, C., Bardy, B., \& Dalla Bella, S. (2018). Rhythmic abilities and musical training in Parkinson's disease: Do they help? Npj Parkinson's Disease, 4(1), 8.

Cohen, J. (1988). Statistical power analysis for the behavioral sciences (2nd ed.). Hillsdale, NJ: Erlbaum.

Colling, L. J., Noble, H. L., \& Goswami, U. (2017). Neural entrainment and sensorimotor synchronization to the beat in children with developmental dyslexia: An EEG study. Frontiers in Neuroscience, 11, 360.

Corriveau, K. H., \& Goswami, U. (2009). Rhythmic motor entrainment in children with speech and language impairments: Tapping to the beat. Cortex, 45(1), 119-130.

Dalla Bella, S., Benoit, C.-E., Farrugia, N., Keller, P. E., Obrig, H., Mainka, S., \& Kotz, S. A. (2017a). Gait improvement via rhythmic stimulation in Parkinson's disease is linked to rhythmic skills. Scientific Reports, 7(1), 42005.

Dalla Bella, S., Dotov, D., Bardy, B., \& Cochen de Cock, V. (2018). Individualization of musicbased rhythmic auditory cueing in Parkinson's disease. Annals of the New York Academy of Science, 1423(1), 308-317.

Dalla Bella, S., Farrugia, N., Benoit, C.-E., Begel, V., Verga, L., Harding, E., \& Kotz, S. A. (2017b). BAASTA: Battery for the assessment of auditory sensorimotor and timing abilities. Behavior Research Methods, 49(3), 1128-1145.

Dauer, R. M. (1983). Stress-timing and syllable-timing reanalyzed. Journal of Phonetics, 11(1), 51-62. 
Ding, N., \& Simon, J. Z. (2014). Cortical entrainment to continuous speech: Functional roles and interpretations. Frontiers in Human Neuroscience, 8, 311.

Drake, C., Jones, M. R., \& Baruch, C. (2000). The development of rhythmic attending in auditory sequences: Attunement, referent period, focal attending. Cognition, 77(3), 251-288.

Essens, P. J., \& Povel, D.-J. (1985). Metrical and nonmetrical representations of temporal patterns. Perception \& Psychophysics, 37(1), 1-7.

Faul, F., Erdfelder, E., Lang, A-G., \& Buchner, A. (2007). G*power 3: A flexible statistical power analysis program for the social, behavioral, and biomedical sciences. Behavior Research Methods, 39(2), 175-191.

Flaugnacco, E., Lopez, L., Terribili, C., Montico, M., Zoia, S., \& Schön, D. (2015). Music training increases phonological awareness and reading skills in developmental dyslexia: A randomized control trial. PloS One, 10(9), e0138715.

Flaugnacco, E., Lopez, L., Terribili, C., Zoia, S., Buda, S., Tilli, S., Monasta, L., Montico, M., Sila, A., Ronfani, L., \& Schön, D. (2014). Rhythm perception and production predict reading abilities in developmental dyslexia. Frontiers in Human Neuroscience, 8, 392.

Fotidzis, T. S., Moon, H., Steele, J. R., \& Magne, C. L. (2018). Cross-modal effects of rhythm on visual word recognition and its relationships to music aptitude and reading achievement. Brain Sciences, 8(12), 210.

Fujioka, T., Trainor, L. J., Large, E. W., \& Ross, B. (2012). Internalized timing of isochronous sounds is represented in neuromagnetic beta oscillations. The Journal of Neuroscience, 32(5), 1791-1802.

Giraud, A. L., \& Poeppel, D. (2012). Cortical oscillations and speech processing: Emerging computational principles and operations. Nature Neuroscience, 15(4), 511-517.

Gordon, R. L., Jacobs, M. S., Schuele, C. M., \& McAuley, J. D. (2015). Perspectives on the rhythmgrammar link and its implications for typical and atypical language development. Annals of the New York Academy of Science, 1337(1), 16-25.

Gordon, R. L., Shivers, C. M., Wieland, E. A., Kotz, S. A., Yoder, P. J., \& McAuley, J. D. (2015). Musical rhythm discrimination explains individual differences in grammar skills in children. Developmental Science, 18(4), 635-644.

Grahn, J. A. (2012). See what I hear? Beat perception in auditory and visual rhythms. Experimental Brain Research, 220(1), 55-61.

Grahn, J. A., \& Brett, M. (2007). Rhythm and beat perception in motor areas of the brain. Journal of Cognitive Neuroscience, 19(5), 893-906.

Grahn, J. A., \& Schuit, D. (2012). Individual differences in rhythmic ability: Behavioral and neuroimaging investigations. Psychomusicology: Music, Mind, and Brain, 22(2), 105-121.

Hidalgo, C., Falk, S., \& Schön, D. (2017). Speak on time! Effects of a musical rhythmic training on children with hearing loss. Hearing Research, 351, 11-18. 
Hove, M. J., \& Risen, J. L. (2009). It's all in the timing: Interpersonal synchrony increases affiliation. Social Cognition, 27(6), 949-960.

Iversen, J. R., \& Patel, A. D. (2008). The Beat Alignment Test (BAT): Surveying beat processing abilities in the general population. Proceedings of the 10th International Conference on Music Perception and Cognition (ICMPC 10). Sapporo, Japan.

Janata, P. (2009). Music and the self. In R. Haas \& V. Brandes (Eds.), 131-141. Music that works. Vienna: Springer.

Jentschke, S., \& Koelsch, S. (2009). Musical training modulates the development of syntax processing in children. NeuroImage, 47(2), 735-744.

Jones, M. R. (1976). Time, our lost dimension: Toward a new theory of perception, attention and memory. Psychological Review, 83(5), 323-355.

Jones, M. R. (2019). Time will tell: A theory of dynamic attending. New York, NY: Oxford University Press.

Jones, M. R., \& Boltz, M. (1989). Dynamic attending and responses to time. Psychological Review, 96(3), 459-491.

Jones, M. R., Moynihan, H., MacKenzie, N., \& Puente, J. (2002). Temporal aspects of stimulusdriven attending in dynamic arrays. Psychological Science, 13(4), 313-319.

Jonides, J., \& Mack, R. (1984). On the cost and benefit of cost and benefit. Psychological Bulletin, 96 (1), 29-44.

Kirschner, S., \& Tomasello, M. (2010). Joint music making promotes prosocial behavior in 4year- old children. Evolution and Human Behavior, 31(5), 354-364.

Kotz, S. A., Frisch, S., von Cramon, D. Y., \& Friederici, A. D. (2003). Syntactic language processing: ERP lesion data on the role of the basal ganglia. Journal of the International Neurophysiological Society, 9(7), 1053-1060.

Kotz, S. A., \& Gunter, T. C. (2015). Can rhythmic auditory cuing remediate language-related deficits in Parkinson's disease? Annals of the New York Academy of Science, 1337(1), 62-68.

Kotz, S. A., Gunter, T. C., \& Wonneberger, S. (2005). The basal ganglia are receptive to rhythmic compensating during auditory syntactic processing: ERP patient data. Brain and Language, 95 (1), 70-71.

Kotz, S. A., \& Schwartze, M. (2010). Cortical speech processing unplugged: A timely subcorticocortical framework. Trends in Cognitive Sciences, 14(9), 392-399.

Large, E. W., Herrera, J. A., \& Velasco, M. J. (2015). Neural networks for beat perception in musical rhythm. Frontiers in Systems Neuroscience, 9, 159.

Large, E. W., \& Palmer, C. (2002). Perceiving temporal regularity in music. Cognitive Science, 26 (1), 1-37. 
Large, E. W., \& Snyder, J. S. (2009). Pulse and meter as neural resonance. The Neuroscience and Music III - Disorders and Plasticity: Annals of the New-York Academy of Science, 1169, 46-57.

Law, L. N. C., \& Zentner, M. (2012). Assessing musical abilities objectively: Construction and validation of the profile of music perception skills. PloS One, 7(12), e52508.

Leow, L.-A., Parrott, T., \& Grahn, J. (2014). Individual differences in beat perception affect gait responses to low- and high-groove music. Frontiers in Human Neuroscience, 8, 811.

Macmillan, N. A, \& Creelman, C. D. (1991). Detection theory: A user's guide. Cambridge, England: Cambridge University Press.

Madison, G. (2006). Experiencing groove induced by music: Consistency and phenomenology. Music Perception, 24(2), 201-208.

Mas-Herrero, E., Marco-Pallares, J., Lorenzo-Seva, U., Zatorre, R. J., \& Rodriguez-Fornells, A. (2013). Individual differences in music reward experiences. Music Perception, 31(2), 118-138.

Mathôt, S., Schreij, D., \& Theeuwes, J. (2012). OpenSesame: An open-source, graphical experiment builder for the social sciences. Behavior Research Methods, 44(2), 314-324.

McAuley, J. D., Jones, M. R., Holub, S., Johnston, H. M., \& Miller, N. S. (2006). The time of our lives: Life span development of timing and event tracking. Journal of Experimental Psychology: General, 135(3), 348-367.

Musacchia, G., Sams, M., Skoe, E., \& Kraus, N. (2007). Musicians have enhanced subcortical auditory and audiovisual processing of speech and music. PNAS, 104(40), 15894-15898.

New, B., Pallier, C., Ferrand, L., \& Matos, R. (2001). Une base de données lexicales du français contemporain sur internet: LEXIQUE TM . L'Année Psychologique, 101(3), 447-462.

Overy, K. (2000). Dyslexia, temporal processing and music: The potential of music as an early learning aid for dyslexic children. Psychology of Music, 28(2), 218-229.

Patel, A. D. (2008). Music, language and the brain. New York: Oxford University Press.

Peretz, I., Gosselin, N., Tillmann, B., Cuddy, L. L., Gagnon, B., Trimmer, C. G., Paquette, S., \& Bouchard, B. (2008). On-line identification of congenital amusia. Music Perception, 25(4), 331343.

Pitt, M. A., \& Samuel, A. G. (1990). The use of rhythm in attending to speech. Journal of Experimental Psychology: Human Perception and Performance, 16(3), 564-573.

Port, R. F. (2003). Meter and speech. Journal of Phonetics, 31(3-4), 599-611.

Pressing, J. (2002). Black atlantic rhythm: Its computational and transcultural foundations. Music Perception, 19(3), 285-310.

Przybylski, L., Bedoin, N., Krifi-Papoz, S., Herbillon, V., Roch, D., Léculier, L., Kotz, S. A., \& Tillmann, B. (2013). Rhythmic auditory stimulation influences syntactic processing in children with developmental language disorders. Neuropsychology, 27(1), 121-131. 
Quené, H., \& Port, R. (2005). Effects of timing regularity and metrical expectancy on spokenword perception. Phonetica, 62(1), 1-13.

Repp, B. H. (2010). Sensorimotor synchronization and perception of timing: Effects of music training and task experience. Human Movement Science, 29(2), 200-213.

Roncaglia-Denissen, M. P., Schmidt-Kassow, M., \& Kotz, S. A. (2013). Speech rhythm facilitates syntactic ambiguity resolution: ERP evidence. PloS One, 8(2), e56000.

Saliba, J., Lorenzo-Seva, U., Marco-Pallares, J., Tillmann, B., Zeitouni, A., \& Lehmann, A. (2016). French validation of the Barcelona music reward questionnaire. PeerJ, 4, e1760.

Schellenberg, E. G. (2005). Music and cognitive abilities. Current Directions in Psychological Science, 14(6), 317-320.

Schmidt-Kassow, M., \& Kotz, S. A. (2008). Entrainment of syntactic processing? ERP-responses to predictable time intervals during syntactic reanalysis. Brain Research, 1226, 144-155.

Schön, D., \& Tillmann, B. (2015). Short- and long-term rhythmic interventions: Perspectives for language rehabilitation. Annals of the New York Academy of Science, 1337(1), 32-39.

Sowinski, J., \& Dalla Bella, S. (2013). Poor synchronization to the beat may result from deficient auditory-motor mapping. Neuropsychologia, 51(10), 1952-1963.

Stupacher, J., Hove, M. J., \& Janata, P. (2016). Audio features underlying perceived groove and sensorimotor synchronization in music. Music Perception, 33(5), 571-589.

Su, Y.-H., \& Pöppel, E. (2012). Body movement enhances the extraction of temporal structures in auditory sequences. Psychological Research, 76(3), 373-382.

Thomson, J. M., \& Goswami, U. (2008). Rhythmic processing in children with developmental dyslexia: Auditory and motor rhythms link to reading and spelling. Journal of Physiology-Paris, 102(1-3), 120-129.

Tillmann, B,. Janata, P., Birk, J., \& Bharucha, J. J. (2003). The costs and benefits of tonal centers for chord processing. Journal of Experimental Psychology: Human Perception and Performance, 29 (2), 470-482.

Tranchant, P., Vuvan, D. T., \& Peretz, I. (2016). Keeping the beat: A large sample study of bouncing and clapping to music. PloS One, 11(7), e0160178.

Valdesolo, P., Ouyang, J., \& DeSteno, D. (2010). The rhythm of joint action: Synchrony promotes cooperative ability. Journal of Experimental Social Psychology, 46(4), 693-695.

Wiltermuth, S. S., \& Heath, C. (2009). Synchrony and cooperation. Psychological Science, 20(1), 1.

Woodruff Carr, K., White-Schwoch, T., Tiernay, A. T., Strait, D. L., \& Kraus, N. (2014). Beat synchronization predicts neural speech encoding and reading readiness in preschoolers. PNAS, 111(40), 14559-14564. 